\title{
Lung function 8-18 years after intermittent positive pressure ventilation for hyaline membrane disease
}

\author{
Martin J K de Kleine, Carel M Roos, Wim J Voorn, Henk M Jansen, Janna G Koppe
}

\begin{abstract}
Lung function and respiratory symptoms were studied in 40 children aged 8-18 years who had been ventilated for hyaline membrane disease after birth; 11 had had bronchopulmonary dysplasia. Also studied were 38 age matched children who had had hyaline membrane disease but had not required ventilation, 25 unmatched children who were born prematurely but did not develop hyaline membrane disease, and 39 randomly selected pupils of similar age. There was no difference in thoracic gas volume, total lung capacity, inspiratory vital capacity, residual volume, or transfer factor for carbon monoxide between the groups. Respiratory symptoms during the three years before the study and the frequency of clinically diagnosed asthma in patients and their family were similar in all the children with hyaline membrane disease irrespective of whether they had been ventilated or had had bronchopulmonary dysplasia. The children with bronchopulmonary dysplasia, however, had a lower forced expiratory volume in one second $\left(F E V_{1}\right)$ before bronchodilator $(73 \%$ predicted) than the other groups (88-95\% predicted). Children who had required ventilation had lower values for specific airways conductance (sGaw) and a greater increase in $\mathrm{FEV}_{1}\left(\triangle F E V_{1}\right)$ after salbutamol (13\%) than non-ventilated children (6\%); $\triangle F E V_{1}$ was associated with the peak pressure of intermittent positive pressure ventilation, a family history of asthma and a history of wheezing, recurrent respiratory illnesses, and a doctor's diagnosis of asthma during the three years before the study. These findings indicate that after eight years of age patients with bronchopulmonary dysplasia have more reversible airways obstruction, compatible with increased bronchial smooth muscle tone.
\end{abstract}

Intermittent positive pressure ventilation has been standard treatment for hyaline membrane disease since the $1960 \mathrm{~s}^{1}$ From $10 \%$ to $20 \%$ of survivors develop bronchopulmonary dysplasia, ${ }^{2}$ a chronic lung disease first described by Northway. ${ }^{3}$ Bronchopulmonary dysplasia has been attributed to the hyperoxia (chemotrauma) and high peak pressure (barotrauma) experienced during intermittent positive pressure ventilation. ${ }^{4}$ The lungs show alternating areas of emphysematous and collapsed alveoli, bronchiolar mucosal metaplasia and hyperplasia, peribronchial smooth muscle hypertrophy, interstitial proliferation of fibroblasts, and hypertrophy of the media of arterioles. ${ }^{3}$

Most studies of the long term effects of lung injury in neonates ventilated mechanically for hyaline membrane disease have been carried out in children of primary school age. ${ }^{5-13}$ Normal lung volumes were found in almost all children. Some authors reported airways obstruction in ventilated infants, ${ }^{12}$ especially those with bronchopulmonary dysplasia, ${ }^{11}$ but other authors found no relation between pulmonary function and the use of intermittent positive pressure ventilation. ${ }^{56810}$ Longitudinal studies have shown a tendency toward improvement in lung function with time (when expressed as percentages of predicted values) in children who had been ventilated, ${ }^{14}$ but not in those with bronchopulmonary dysplasia.

We started to use intermittent positive pressure ventilation in newborn infants with hyaline membrane disease in 1967, and have studied lung function and respiratory symptoms in 40 survivors aged 8-18 years. We postulated that the effects of lung injury caused by intermittent positive pressure ventilation for hyaline membrane disease during the neonatal period would have disappeared completely in children over 8 years old.

\section{Methods}

SUBJECTS

From 1967 to 1977360000 infants were born in the north western part of The Netherlands, some 19000 of whom were cared for in the University Hospital of Amsterdam. ${ }^{15}$ Of 524 infants treated for hyaline membrane disease (227 born in the University Hospital and 297 born in other hospitals), 247 were ventilated. Sixty three of the ventilated infants survived the first year of life. The addresses of eight children could not be traced and 14 children refused to participate. Follow up lung function studies were carried out therefore on 41 children. One boy, who did not have bronchopulmonary dysplasia, was unable to perform the tests because of neurological problems. Bronchopulmonary dysplasia was diagnosed on the basis of dependence on oxygen therapy for more than 28 days after intermittent positive pressure ventilation for 
hyaline membrane disease. ${ }^{16}$ Eleven children fulfilled these criteria.

Follow up data are presented for 40 children who had undergone ventilation, 11 with and 29 without bronchopulmonary dysplasia. All the infants had been ventilated with a constant flow, time cycled, pressure controlled infant ventilator (Loos and Company, Amsterdam) ${ }^{17}$ For the children with and without bronchopulmonary dysplasia the mean duration of intermittent positive pressure ventilation was 9.0 (range 1.8-36) and 2.9 (range 0.8-6.9) days and the mean duration of supplemental oxygen therapy was 72.5 (range 32-182) and 10.5 (range 6-24) days. The 40 children studied did not differ significantly from the 23 children unavailable for study with respect to perinatal factors. The clinical characteristics of the various groups of children are shown in table 1.

Three additional groups of children were also studied for comparison.

1 Forty one children who had had hyaline membrane disease but had not been ventilated, matched for gestational age, present age, and sex. Two boys could not be matched for sex and were replaced by girls, and two other cases could not be matched at all. One girl failed to perform the tests for emotional reasons. Control data were therefore obtained for 38 children.

2 Twenty five children (23 preterm and two full term) who had had neither hyaline membrane disease nor other perinatal respiratory problems and were born during the years 1974-7. The mothers of these children had been admitted to hospital because of premature labour and had been enrolled in a clinical trial to test the effect of antenatally administered corticosteroids on the incidence and prognosis of hyaline membrane disease. ${ }^{18} 19$ These children have been designated "reference group '74-77."

3 Thirty nine randomly selected pupils, aged 12-17, in their second and fourth years at a secondary school in Amsterdam.

Written informed consent for the investigations was obtained from the parents or child when appropriate. The medical-ethical committee of the University Hospital of Amsterdam found the study to be in accordance with the convention of Helsinki.

LUNG FUNCTION MEASUREMENTS

Inspiratory vital capacity (IVC) and forced expiratory volume in one second $\left(\mathrm{FEV}_{1}\right)$ were measured with a water sealed spirometer (Lode instruments, Groningen, Netherlands) with the subject seated. At least three measurements were performed; values had to vary by less than $150 \mathrm{ml}$, and the largest volume was recorded. Results were obtained before and 20 minutes after a 0.75 minute inhalation with salbutamol $(5 \mathrm{mg} / \mathrm{ml})$ from a nebuliser (Hudson, Temecula, California). The increase in $F_{1} V_{1}$ after salbutamol was expressed as a percentage of the value before bronchodilatation $\left(\triangle \mathrm{FEV} \mathrm{V}_{1}\right)$. Thoracic gas volume (TGV) and airways resistance (Raw) were measured with a volume constant body plethysmograph (Jaeger, Wurzburg, Germany), from which total lung capacity (TLC), residual volume (RV), and specific airways conductance (sGaw) were calculated. Body plethysmography was performed after inhalation of salbutamol. Volumes were expressed as percentages of the predicted values for sex and height. ${ }^{2021}$ Transfer factor for carbon monoxide (TLCO) was measured by the single breath diffusion method of Ogilvie et al. ${ }^{22} 23$

The children with hyaline membrane disease who had not been ventilated had the same tests as the children who had been ventilated. The reference group '74-77 had spirometric studies before and after salbutamol; the secondary school pupils had spirometric studies without salbutamol only.

The technicians who performed the studies were unaware of the neonatal history of the children. The secondary school pupils were studied as a separate cohort.

\section{CLINICAL INFORMATION}

The follow up records of the patients who had had hyaline membrane disease were used to obtain data on respiratory illnesses during the first four years of life after discharge from hospital, the number of episodes of pneumonia, hospital admissions for respiratory infections, the use of beta adrenergic or anticholinergic drugs for more than three months, and the need for respiratory physiotherapy for more than three months. Data about respiratory diseases and symptoms were not available for the reference groups who had not had hyaline membrane disease.

Information was obtained about respiratory symptoms such as cough, congestion or mucus, and wheezing during the last three years, and about doctors' diagnosis of asthma or allergy

Table 1 Mean (SD) number, sex, gestational age, birth weight, age and height of ventilated children (with and without bronchopulmonary disease (BPD)) and non-ventilated children with hyaline membrane disease, reference group 1974-1977, and healthy secondary school pupils (no significant differences between ventilated (including BPD) and non-ventilated children)

\begin{tabular}{|c|c|c|c|c|c|}
\hline & \multicolumn{2}{|l|}{ Ventilated } & \multirow{2}{*}{$\begin{array}{l}\text { Non- } \\
\text { ventilated }\end{array}$} & \multirow{2}{*}{$\begin{array}{l}\text { Ref group } \\
\text { '74-77 }\end{array}$} & \multirow[b]{2}{*}{ Pupils } \\
\hline & $B P D$ & Non-BPD & & & \\
\hline $\begin{array}{l}\text { Number } \\
\text { Male } \\
\text { Gestational age (wk) } \\
\text { Birth weight (g) } \\
\text { Age at follow up (y) } \\
\text { Height (cm) }\end{array}$ & $\begin{array}{c}11 \\
8(73 \%) \\
30 \cdot 6(2 \cdot 0) \\
1673(340) \\
13 \cdot 4(3 \cdot 1) \\
158(18)\end{array}$ & $\begin{array}{c}29 \\
19(66 \%) \\
32 \cdot 2(1 \cdot 8) \\
1952(460) \\
12 \cdot 3(2 \cdot 9) \\
151(14)\end{array}$ & $\begin{array}{c}38 \\
24(63 \%) \\
31 \cdot 8(1 \cdot 9) \\
1809(419) \\
12 \cdot 8(2 \cdot 7) \\
155(17)\end{array}$ & $\begin{array}{c}25 \\
12(48 \%) \\
34 \cdot 2(3 \cdot 5) \\
2285(737) \\
10 \cdot 7(0 \cdot 6) \\
146(7)\end{array}$ & $\begin{array}{l}39 \\
20(51 \%) \\
- \\
- \\
13 \cdot 7(1 \cdot 6) \\
165(11)\end{array}$ \\
\hline
\end{tabular}


Table 2 Results of spirometric studies in ventilated children (with and without bronchopulmonary dysplasia (BPD)) and non-ventilated children with hyaline membrane disease, reference group 1974-7, and healthy pupils (inspiratory vital capacity (IVC) and FEV, before and after bronchodilatation expressed as percentages of predicted values, ${ }^{20}{ }^{21} \triangle F E V_{1}$ expressed as percentage increase in value before bronchodilatation)

\begin{tabular}{|c|c|c|c|c|c|c|c|c|c|c|}
\hline & \multicolumn{4}{|c|}{ Ventilated } & & & & & & \\
\hline & \multicolumn{2}{|c|}{$B P D$} & \multicolumn{2}{|c|}{ Non-BPD } & \multicolumn{2}{|c|}{ Non-ventilated } & \multicolumn{2}{|c|}{ Reference group'74-77 } & \multicolumn{2}{|c|}{ Pupils } \\
\hline & $(n)$ & $\operatorname{Mean}(S D)$ & $(n)$ & $\operatorname{Mean}(S D)$ & $(n)$ & Mean $(S D)$ & $(n)$ & $\operatorname{Mean}(S D)$ & $(n)$ & $\operatorname{Mean}(S D)$ \\
\hline IVC & (11) & $85(14)$ & (27) & $89(12)$ & (38) & $93(12)$ & (25) & $93(10)$ & (39) & $94(9)$ \\
\hline $\begin{array}{l}\mathrm{FEV}_{1} \\
\text { Before bronchodilatation } \\
\text { After bronchodilatation } \\
\triangle \mathrm{FEV}\end{array}$ & $\begin{array}{l}(11) \\
(11) \\
(11)\end{array}$ & $\begin{array}{l}73(17) \\
81(16) \\
13(10)\end{array}$ & $\begin{array}{l}(27) \\
(22) \\
(24)\end{array}$ & $\begin{array}{l}88^{\star}(15) \\
94^{\star}(12) \\
12(17)\end{array}$ & $\begin{array}{l}(38) \\
(37) \\
(37)\end{array}$ & $\begin{array}{l}92^{\star \star}(17) \\
97^{\star}(15) \\
6^{\star \star \star}(10)\end{array}$ & $\begin{array}{l}(25) \\
(25) \\
(25)\end{array}$ & $\begin{array}{l}95^{\star \star \star}(10) \\
98^{\star \star}(12) \\
3^{\star \star \star} \dagger(4)\end{array}$ & (39) & $95^{\star \star \star}(12)$ \\
\hline
\end{tabular}

${ }^{\star} \mathrm{p}<0.05,{ }^{\star \star} \mathrm{p}<0.01,{ }^{\star \star \star} \mathrm{p}<0.001$, in the comparison with the bronchopulmonary dysplasia group; $\dagger \mathrm{p}<0.01$ in the comparison with the non-BDP group (Mann-Whitney test).

$\triangle F E V_{1}$ (the increase in
FEV, 20 minutes after
bronchodilatation with
salbutamol, expressed as
percentage of the value
before bronchodilatation)
of ventilated children
(both with and without
bronchopulmonary
dysplasia (group I), non-
ventilated children with
hyaline membrane disease
(group II), and a
reference group of
prematurely born children
without perinatal
respiratory problems
(group III).
the parents. This included questions from the children's questionnaire of the American Thoracic Society*.24 Doctors' diagnoses of asthma or allergy in the parents and siblings of the 78 patients with hyaline membrane disease were obtained from the questionnaire.

Perinatal data were obtained from the patient's hospital chart for all infants with hyaline membrane disease whether or not they

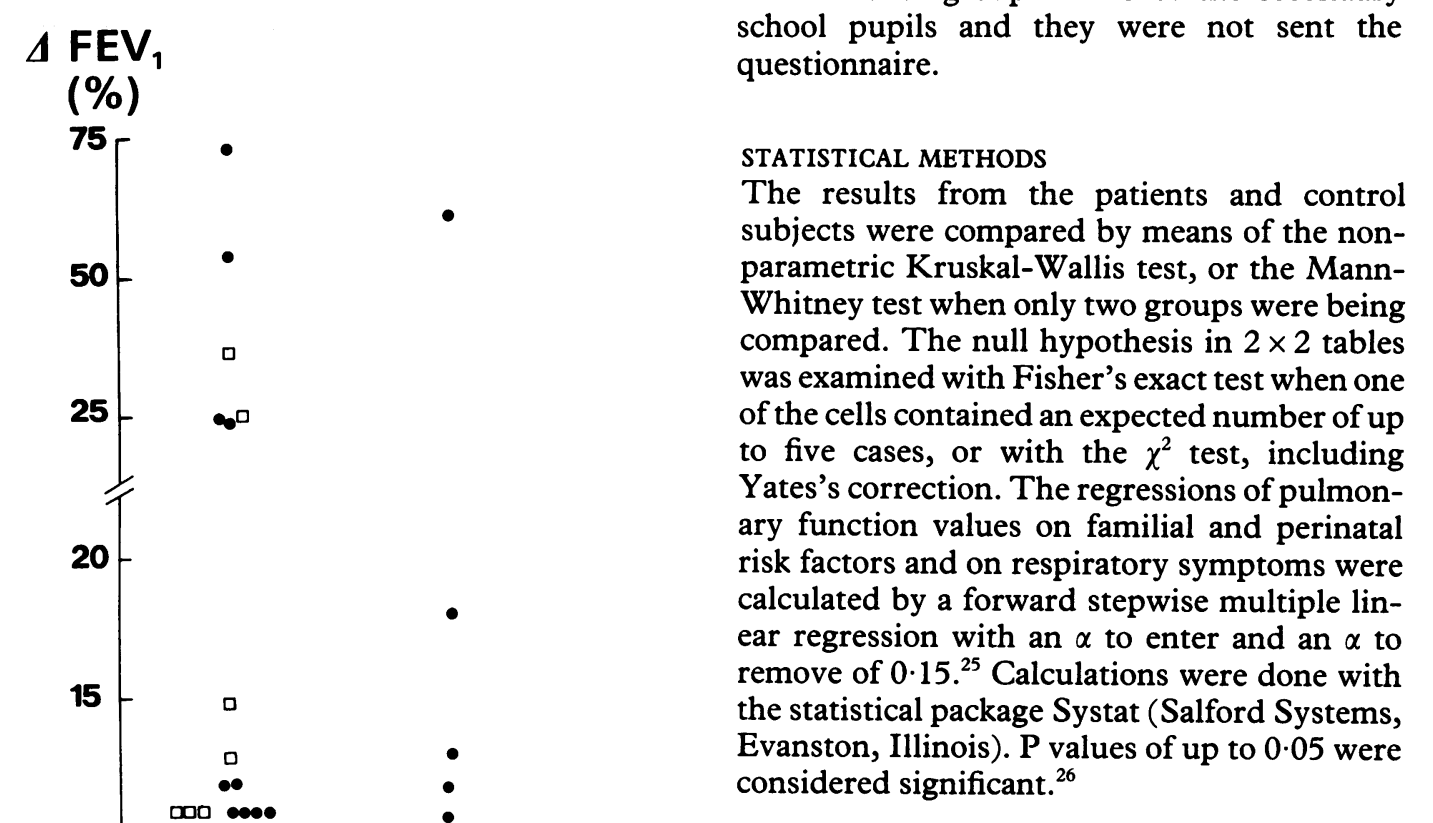

$\therefore$ Results

$\infty$ LUNG FUNCTION - ventilated infants and the control groups. - than that of the children with bronchopulmon-
The inspiratory vital capacity did not differ between the different groups (table 2). The $\mathrm{FEV}_{1}$ was lower in the children with bronchopulmonary dysplasia than in all other groups; it did not differ between the other $\triangle \mathrm{FEV}_{1}$ after salbutamol was higher in the ventilated children with and without bronchopulmonary dysplasia than in the reference group '74-77; in non-ventilated infants with hyaline membrane disease $\triangle F E V_{1}$ was lower

were ventilated. These included gestational age weight, Apgar score five minutes after birth, capillary pH one hour after birth, the lowest of intermittent positive pressure ventilation, maximal peak pressure applied during a inim of 12 hours, and hours of supexygen and of more than $80 \%$ oxygen. Perinatal data were not obtained from the reference group '74-78 or the secondary pupils and they were not sent the STATISTICAL METHODS subjects were compared by means of the nonYates's correction. The regressions of pulmonrisk factors and on respiratory symptoms were ear regression with an $\alpha$ to enter and an $\alpha$ to from a questionnaire in Dutch that was sent to 
Table 3 Specific airway conductance (sGaw, \% predicted ${ }^{2021}$ ) after salbutamol and carbon monoxide transfer factor (TLCO) ( $\left.\mathrm{ml} \mathrm{min}^{-1} \mathrm{kPa}\right)$ in ventilated children (with and without bronchopulmonary dysplasia (BPD)) and non-ventilated children

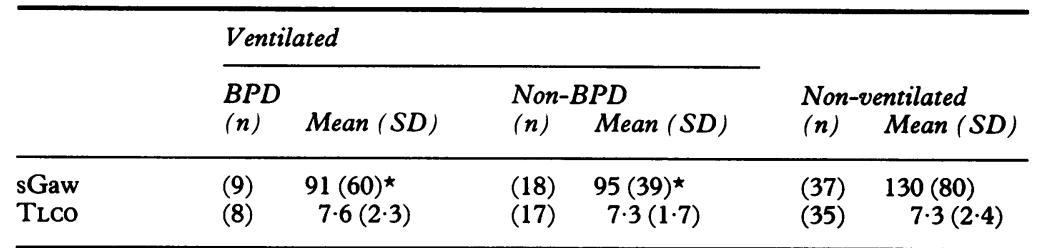

*Differs from values in non-ventilated children; $p<0.05$ (Mann-Whitney test).

ary dysplasia but did not differ from the other control infants. Overall half of the children who had been ventilated had a $\triangle \mathrm{FEV}_{1}$ above $10 \%$ (figure).

sGaw values after salbutamol were lower in the children with hyaline membrane disease who had been ventilated than in those who had not (table 3 ). sGaw was below $80 \%$ predicted in six of nine children with and in nine of 18 children without bronchopulmonary dysplasia who had been ventilated compared with only five of 37 non-ventilated children with hyaline membrane disease. There were no significant differences in TGV, TLC, or RV. All groups of children had TLCO values within the reference ranges of Knudson et al. ${ }^{23}$

\section{CLINICAL INFORMATION}

During the first four years after discharge from hospital the children with bronchopulmonary dysplasia were more likely to be treated for pneumonia, admitted to hospital for respiratory infections, treated with bronchodilators, and have respiratory physiotherapy than children who had been ventilated but had no bronchopulmonary dysplasia (table 4). Among the children with hyaline membrane disease but no bronchopulmonary dysplasia there were no significant differences between those who had and had not been ventilated (table 4).

Respiratory symptoms during the previous three years were similar in patients with hyaline membrane disease who had been ventilated (with or without bronchopulmonary dysplasia) and those who had not, with the exception of exercise induced wheezing, which was more common in children who had had bronchopulmonary dysplasia (four of 11 children compared with none of 29 children who had been ventilated but had no bronchopulmonary dys-

Table 4 Frequency of respiratory symptoms after discharge from hospital during the first four years of life in 11 ventilated children with bronchopulmonary dysplasia (BPD), 29 ventilated infants without BPD, and 38 non-ventilated infants with hyaline membrane disease

\begin{tabular}{|c|c|c|c|}
\hline & \multicolumn{2}{|l|}{ Ventilated } & \multirow{2}{*}{$\begin{array}{l}\text { Non-ventilated } \\
(n=38)\end{array}$} \\
\hline & $B P D(n=11)$ & Non-BPD $(n=28)$ & \\
\hline Pneumonia & $9 \star \star$ & 10 & 6 \\
\hline $\begin{array}{l}\text { Admitted to hospital for } \\
\text { respiratory infections }\end{array}$ & $11^{\star \star \star}$ & 7 & 4 \\
\hline Bronchodilating agents & $6^{\star \star}$ & 3 & 7 \\
\hline Physiotherapy & $7^{\star}$ & 7 & 4 \\
\hline
\end{tabular}

$\mathrm{p}<0.05,{ }^{\star \star} \mathrm{p}<0.01,{ }^{\star \star \star} \mathrm{p}<0.001$ (Fisher's exact test). plasia and four of 39 non-ventilated children with hyaline membrane disease; $p<0.01$ ).

Asthma diagnosed from clinical symptoms did not differ significantly in the three groups (two of 11 children with bronchopulmonary dysplasia, two of 29 ventilated children with no bronchopulmonary dysplasia, five of 38 nonventilated children with hyaline membrane disease; $\mathrm{p}>0.05$ ).

The frequency of asthma and allergy was evenly distributed in the first degree relatives of children who had been ventilated with or without bronchopulmonary dysplasia and children with hyaline membrane disease who had not been ventilated $(0,4,5 ; 1,10$, and 16$)$.

RISK FACTORS, RESPIRATORY SYMPTOMS, AND LUNG FUNCTION IN 78 CHILDREN WITH HYALINE MEMBRANE DISEASE

$\mathrm{FEV}_{1}$ was related to the need for respiratory physiotherapy in the first four years of life $(\mathrm{p}<0.01)$ and the symptom "wheezing apart from colds" during the three years before the lung function studies $(p<0.001)$. These two factors explained $32 \%$ of the variance. $\Delta \mathrm{FEV}_{1}$ was related to the frequency of asthma in first degree family members $(p<0.01)$, the peak pressure during intermittent positive pressure ventilation ( $p<0.01)$, "wheezing with or without colds" ( $p<0.001$ ), "respiratory illnesses which had kept the child from his usual activities for as much as three days" during the last three years before the lung function studies $(p=0.001)$ and the "doctor's diagnosis of asthma" ( $p<0.001)$. These five factors explained $65 \%$ of the variance. sGaw was related to a history of pneumonia ( $p<0.05$ ) and "cough" and "congestion apart from colds" during the three years before the lung function studies $(p<0.001$ and $<0.01)$. These three factors explained $43 \%$ of the variance.

\section{Discussion}

Children who were ventilated for hyaline membrane disease after birth were examined between the ages of 8 and 18 years for the persistence of "unresolved lung injury." Fourteen children refused to participate in the study. There was no evidence that either excess or lack of symptoms caused their refusal. As the Dutch health system is freely available, our follow up study is unlikely to have been biased towards patients seeking medical help or advice.

Reference values use allometric relationships between stature and lung volumes. During the pubertal growth spurt, which starts earlier in boys than in girls, neither total lung capacity nor its subdivisions grow in proportion to thorax dimensions or stature, the growth spurt of the thorax and lung lagging behind that for standing height. ${ }^{27}{ }^{28} \mathrm{We}$ therefore matched children with hyaline membrane disease who were ventilated and not ventilated for both sex and age. The mean age of the reference group '74-77 was below the age when the growth spurt starts and the mean age of the secondary school pupils slightly above. Despite this the 
differences between the two reference groups were negligible.

We used distribution free statistical methods to test our hypothesis because the raw data did not show a Gaussian distribution. Having postulated that complete recovery of the lung injury would occur, we found that $\mathrm{FEV}_{1}$ and sGaw were decreased and $\triangle F E_{1}$ increased in the children with hyaline membrane disease, especially those with bronchopulmonary dysplasia. Lung volumes and transfer factor for carbon monoxide were normal, however; these results are in agreement with the data reported in younger children. ${ }^{11}$

The differences in $\mathrm{FEV}_{1}$ cannot be explained by the variability of the measurement. In a later study of methacholine responsiveness in 15 of the children in this study the mean difference in $\mathrm{FEV}_{1}$ before and after they had inhaled nebulised phosphate buffer was $1 \%$ (range $-3.5 \%$ to $+3.6 \%$, SD $1.7 \%$ ).

The children with a low $\mathrm{FEV}_{1}$ showed a greater response to salbutamol. The mean increase in $\mathrm{FEV}_{1}$ of $3 \%$ after salbutamol in our control group is similar to previous findings in a normal population. ${ }^{29}{ }^{30}$ An increase in $\mathrm{FEV}_{1}$ of $10 \%$ or more occurred in half of the children who had been ventilated whether or not they had had bronchopulmonary dysplasia. These results suggest that resting bronchial smooth muscle tone is increased in children with hyaline membrane disease after ventilation.

The abnormalities in pulmonary function were found primarily in children with bronchopulmonary dysplasia, suggesting that the factors that caused bronchopulmonary dysplasia are also responsible for the persistence of abnormality in lung function. Goetzman ${ }^{31}$ proposed four elements in the pathogenesis of bronchopulmonary dysplasia-namely, a susceptible host, early acute lung damage, secondary lung injury by oxidants or proteolytic enzymes or both, and abnormal healing by hyperoxia, hypoxia, and interstitial fibrosis.

Some studies have documented increased airways resistance and decreased specific airways conductance as early as two to four days after birth in ventilated infants who went on to develop bronchopulmonary dysplasia. ${ }^{32-34}$ If these infants are those who have airways obstruction in later life, like our patients, the theory of a susceptible host becomes more convincing. The influence of a familial factor has also been suggested by Bertrand et al. ${ }^{35}$ They found an increased incidence of bronchial hyperresponsiveness in parents and siblings of children with persistent pulmonary sequelae of hyaline membrane disease and proposed that premature birth and persistent pulmonary sequelae had a common cause. In a prospective study of 198 pregnant women with asthma, however, the incidence of premature birth was not increased. ${ }^{36}$ The prevalence of asthma was the same in our patients as in a random population ${ }^{37}$ and a family history of asthma was similar in ventilated and non-ventilated children. Our study was not designed to challenge or confirm the hypothesis of Bertrandt et al, but our data do not support their theory.
The element of lung injury has been well established since the introduction of the term bronchopulmonary dysplasia. ${ }^{34}$ This accounts for a high incidence of respiratory diseases in our patients with bronchopulmonary dysplasia during the first four years after discharge. The normal lung volumes, even in the children with bronchopulmonary dysplasia, exclude the persistence of appreciable fibrosis.

After the age of 8 years the patients who had had bronchopulmonary dysplasia did not have more respiratory symptoms than children with hyaline membrane disease who had not been ventilated, indicating further improvement in these children. Children were labelled asthmatic when they had been diagnosed as such on the basis of clinical symptoms according to the American Thoracic Society questionnaire before entry into the study. Other authors have defined asthma on the basis of a histamine provocation test or $\Delta F E V_{1}$. Salome et ${ }^{\beta 7}$ found bronchial hyperresponsiveness in $6.7 \%$ of children without symptoms of asthma, whereas $5.6 \%$ of children with asthma did not show bronchial hyperresponsiveness. In our study four of 40 ventilated children had been diagnosed as asthmatic and 17 of 35 children had a $\triangle \mathrm{FEV}_{1}$ greater than $10 \%$ (in six it was greater than $25 \%$ ). Thus a child with an increase in FEV $_{1}$ of $10-25 \%$ after salbutamol does not necessarily receive the clinical diagnosis of asthma. We found a relation between respiratory symptoms and indices of chronic obstructive pulmonary disease, as shown previously ${ }^{3738}$; but symptoms did not discriminate between children with and without bronchopulmonary dysplasia whereas $\mathrm{FEV}_{1}$ did. The only exception was exercise induced wheezing, which Bader et al also found to be present in half of their patients with bronchopulmonary dysplasia. ${ }^{11}$

In the multivariate analysis of perinatal factors of children with hyaline membrane disease $\mathrm{FEV}_{1}$ was not associated with gestational age or birth weight. This is not in keeping with the results of Mansell et al, who found gestational age the only significant factor in persistent lung abnormalities. ${ }^{10}$

Although some children had abnormal lung function, none was handicapped by pulmonary insufficiency at the time of follow up. The maximum duration of mechanical ventilation for these children was 36 days, indicating that very severe bronchopulmonary dysplasia, as occurs now, was not present.

Modern techniques of assisted ventilation, and even the introduction of artificial surfactant, have not reduced the damage to neonatal lungs. On the contrary, because assisted ventilation has increased the number of low birthweight survivors and bronchopulmonary dysplasia is associated with low gestational age, the frequency of bronchopulmonary dysplasia is still rising. Chronic lung damage in survivors of neonatal intensive care will become an even larger problem in the next few years.

Our results indicate that intermittent positive pressure ventilation can be applied safely when indicated in newborn infants. It is possible, however, that increased bronchial 
smooth muscle tone in infancy and childhood, as seen in the children with bronchopulmonary dysplasia, will result in chronic obstructive lung disease in later life. Longitudinal studies so far have shown a relation between deteriorating lung function and a diagnosis of asthma or smoking. ${ }^{39}$ Further research is needed to determine the long term effects of intermittent positive pressure ventilation.

Our data show that newborn babies ventilated for hyaline membrane disease who subsequently develop bronchopulmonary dysplasia continue to have a reversible obstruction in their airways, suggesting increased bronchial smooth muscle tone. This was not found in non-ventilated survivors of hyaline membrane disease and was intermediate in children with no bronchopulmonary dysplasia who had been ventilated. We conclude that persistence of abnormalities in pulmonary function in premature infants with hyaline membrane disease is not related to prematurity itself and may be related to lung injury in constitutionally prone infants.

We thank Professors S K F Kerrebijn and Marvin Cornblath for advice during the study.

1 Farrell PM, Avery ME. Hyaline membrane disease. State of the art. Am Rev Respir Dis 1975;111:657-88.

2 Bancalari E, Gerhardt T. Bronchopulmonary dysplasia. Ped Clin North Am 1986;33:1-23.

3 Northway WH, Rosan RC, Porter DY. Pulmonary disease following respirator therapy of hyaline membrane disease. N Engl J Med 1967;276:357-68.

4 O'Brodovich HM, Mellins RB. Bronchopulmonary dysplasia. Unresolved neonatal acute lung injury. State of the art. Am Rev Respir Dis 1985;132:694-709.

5 Lamarre A, Linsao L, Reilly BJ, Swyer PR, Levison H. Residual pulmonary abnormalities in survivors of idiopathic respiratory distress syndrome. Am Rev Respir Dis 1973;108:57-61.

6 Heldt GP, McIlroy MB, Hansen TN, Tooley WH. Exercise performance of the survivors of hyaline membrane disease. J Pediatr 1980;96:995-9.

7 Stahlman MT, Hedvall G, Lindstrom D, Snell J. Role of hyaline membrane disease in production of later childhood lung abnormalities. Pediatrics 1982;69:572-6.

8 Coates AL, Desmond K, Willis D, Nogrady MB. Oxygen therapy and long-term pulmonary outcome of respiratory distress syndrome in newborns. Am J Dis Child 1982;136:892-5.

9 MacLuskey IB, Stringer D, Zarfen J, et al. Cardiorespiratory status in long-term survivors of prematurity, with and without hyaline membrane disease. Pediatr Pulmonol 1986;2:94-102.

10 Mansell AL, Driscoll JM, James LS. Pulmonary follow-up of moderately low birth infants with and without respiratory distress syndrome. J Pediatr 1987;110:111-5.

11 Bader D, Ramos AD, Lew CD, Platzker AC, Stabile MW, Keens TG. Childhood sequelae of infant lung disease: Exercise and pulmonary function abnormalities after bronchopulmonary dysplasia. J Pediatr 1987;110:693-9.

12 Riedel F. Long term effects of artificial ventilation in neonates. Acta Paediatr Scand 1987;76:24-9.

13 Driscoll DJ, Kleinberg F, Heise CT, Staats BA. Cardiorespiratory function in asymptomatic survivors of neonatal respiratory distress syndrome. Mayo Clin Proc 1987;62:695-700

14 Gerhardt T, Hehre D, Feller R, Reifenberg L, Bancalari E. Serial determination of pulmonary function in infants with chronic lung disease. J Pediatr 1987;110:448-56.
15 Centraal Bureau voor de Statistiek. Maandstatistiek van de bevolking en de volksgezondheid. Supplement jaaroverzich 1977. 's Gravenhage: Staatsuitgeverij, 1978:87.

16 Tooley WH. Epidemiology of bronchopulmonary dysplasia. $J$ Pediatr 1979;95:851-5.

17 Keuskamp DHG. Premature and newborn ventilation. Int Anesth Clin 1974;12:281-307.

18 Schutte MF, Treffers PE, Koppe JG. The influence of betamethason and orciprenaline on the incidence of respiratory distress syndrome. $\mathrm{Br} J$ Obstet Gynaecol 1980;87:127-31.

19 Smolders-de Haas H, Neuvel J, Schmand B, Treffers PE Koppe JG, Hoeks J. Physical development and medical history of children who were treated antenatally with corticosteroids to prevent respiratory distress syndrome; a 10 to 12 years follow up. Pediatrics 1990;86:58-64.

20 Polgar G, Promadhat V. Pulmonary function testing in children. Philadelphia: Saunders, 1971:254.

21 Zapletal A, Paul T, Samanek M. Pulmonary elasticity in children and adolescents. J Appl Physiol 1976;40:953-61.

22 Ogilvie CM, Forster RE, Blackmore WS, et al. A standardized breath holding technique for the clinical measurement of the diffusing capacity of the lung for carbon monoxide. J Clin Invest 1957;36:1-17.

23 Knudson RJ, Kaltenborn WT, Knudson DE, Burrows B. The single-breath carbon monoxide diffusing capacity. Reference equations derived from a healthy nonsmoking population and effects of hematocrit. Am Rev Respir Dis 1987;135:805-11.

24 Ferris BJ. Epidemiology standardization project. II Recommended respiratory disease questionnaires for use with adults and children in epidemiological research. $\mathrm{Am}$ Rev Respir Dis 1978;118(suppl):36-53.

25 Bendell RB, Afif AA. Comparison of stopping rules in forward "stepwise" regression. Journal of the American Statistic Association 1977;72:46-53.

26 Armitage P, Berry G. Statistical methods in medical research. 2nd ed. Oxford: Blackwell, 1987:94-8.

27 DeGroodt EG, Quanjer PH, Wise ME, van Zomeren BC. Changing relationships between stature and lung volumes during puberty. Respir Physiol 1986;65:139-53.

28 DeGroodt EG, van Pelt W, Borsboom GJJM, Quanjer PH, van Zomeren BC. Growth of lung and thorax dimensions during the pubertal growth spurt. Eur Respir $J$ 1988;1:102-8.

29 Ekwo EE, Weinberger MM, Dusdieker LB, Huntley WH, Rodgers P, Maxwell GA. Airway responses to inhaled isoprotenerol in normal children. Am Rev Respir Dis 1983;127:108-9.

30 Casan P, Roca J, Sanchis J. Spirometric response to a bronchodilator. Reference values for healthy children and adolescents. Bull Eur Physiopathol Respir 1983;19:567-9.

31 Goetzman BW. Understanding bronchopulmonary dysplasia. Am J Dis Child 1986;140:332-4.

32 Litzenberger WA, Dunningham MD, Boyer DJ, Desai NS. Neonatal pulmonary function testing during mechanical ventilation: Serial studies in bronchopulmonary dysplasia [abstract]. Pediatr Res 1982;16:355A.

33 Desai NS, Cunningham MD, Boyer DJ, et al. Predisposing pulmonary dynamics from birth for infants with bronchopulmonary dysplasia [abstract]. Clin Res 1983; 32:908A.

34 Goldman SL, Gerhardt T, Sonni R, et al. Early prediction of chronic lung disease by pulmonary function testing. $J$ Pediatr 1983;102:613-7.

35 Bertrand J-M, Riley SP, Popkin J, Coates AL. The long term pulmonary sequelae of prematurity: the role of familial airway hyperreactivity and the respiratory distress syndrome. N Engl J Med 1985;312:742-5.

36 Stenius-Aarniala B, Piirila P, Teramo K. Asthma and pregnancy: a prospective study of 198 pregnancies. Thorax 1988;43:12-8.

37 Salome CM, Peat JK, Britton WJ, Woolcock AJ. Bronchial hyperresponsiveness in two populations of Australian schoolchildren. I. Relation to respiratory symptoms and diagnosed asthma. Clin Allergy 1987;17:271-81.

38 Rijcken B, Schouten JP, Weiss ST, Speizer FE, van de Lende $R$. The relationship of nonspecific bronchial responsiveness to respiratory symptoms in a random population sample. Am Rev Respir Dis 1987;136:62-8.

39 Lebowitz MD, Holberg CJ, Knudson RJ, Burrows B. Longitudinal study of pulmonary function development in childhood, adolescence, and early adulthood. $\mathrm{Am} \mathrm{Rev}$ Respir Dis 1987;136:69-75. 